\title{
Survival Outcomes of Metastatic Colorectal Cancer Patients in Brunei Darussalam and the Impact of KRAS Mutations
}

\author{
Datul Damit ${ }^{1^{+}}$, Ravi Patnaik ${ }^{2+}$, Liling Chaw ${ }^{1}$, Shir Kiong Lu ${ }^{2}$, Telisinghe Pemasiri Upali ${ }^{3}$, Zen Huat $\mathrm{Lu}^{1}$, \\ Kenneth Kok ${ }^{1}$, Ya Chee Lim $^{1 *}$ \\ ${ }^{\dagger}$ Both authors contributed equally \\ ${ }^{1}$ PAPRSB Institute of Health Sciences, Jalan Tungku Link, Universiti Brunei Darussalam \\ ${ }^{2}$ The Brunei Cancer Centre, Pantai Jerudong Specialist Centre, Brunei Darussalam \\ ${ }^{3}$ Pathology Department, RIPAS Hospital, Brunei Darussalam \\ *Correspondence: yachee.lim@ubd.edu.bn
}

\section{ABSTRACT}

Colorectal cancer (CRC) is the third most common cancer, with rising incidence due to lifestyle and diet. $40 \%$ of CRC cases are found to have KRAS mutations. In this study, we investigate the survival outcome of metastatic Colorectal cancer $\mathrm{mCRC}$ ) patients in Brunei Darussalam restrospectively. Chisquared test was used to compare the survival outcomes of $\mathrm{mCRC}$ patients, and Mann-Whitney $U$ test was used to compare the median ages of both groups. Kaplan-Meier survival curves were drawn and logrank test was used to compare the survival outcome between two groups. There was a total of 105 patients with stage IV CRC being treated during the study period. $81.6 \%(n=62)$ of $m C R C$ patients were found to have the primary tumours on the left side of the colon. 19 of these 26 (73.1\%) mutant KRAS mCRC patients died, while 23 of 50 (46.0\%) wild-type KRAS mCRC patients died at the end of the study period, contributing to death rates of $45.2 \%$ and $54.8 \%$, correspondingly. $30.3 \%(n=23)$ of the study population had a single metastatic site detected (either liver, or lung or any other organs), while $69.7 \%$ $(n=53)$ of the 76 mCRC patients had two (double) or more metastatic sites. $69.2 \%(n=18)$ and $30.8 \%$ $(n=8)$ of the mutant KRAS mCRC patients had mutations within codons 12 and 13 , respectively. To our knowledge, this is the first study in Brunei Darussalam to analyse both the survival outcomes of metastatic CRC patients and those of mutant KRAS mCRC patients. Chi-squared analysis showed a significant difference between the survival outcomes of wild-type KRAS and mutant KRAS mCRC patients ( $p$-value $=0.024$ ). There was a significant difference in the survival outcome between the mutant KRAS mCRC patients with RCC and mutant KRAS mCRC with LCC patients. There was no significant difference between the survival outcomes of mutant $K R A S$ patients with mutations in either codon 12 or 13 of the KRAS gene (Table 3). However, there is a significant difference in the median survival periods between the mutant KRAS mCRC patients with mutations in codon 12 and those with mutation in codon 13 of the KRAS gene ( $p$-value $=0.003$ ). In conclusion, we found that mutant KRAS mCRC patients had a significantly poorer OS, which was shown to be worse when the primary tumours were found at the left side of the colon. Mutant KRAS mCRC patients with mutations in codon 12 were found to have shorter survival median periods than those with mutations within codon 13.

Keywords: colorectal cancer; survival; KRAS; median; codon; metastasis; sided; tumour 


\section{INTRODUCTION}

Globally, colorectal cancer (CRC) is the third most common cancer with 1.8 million cases diagnosed in 2018 alone [1]. The rising incidence of CRC cases is attributable to lifestyle, diet and obesity, while the reduction in mortality cases in developed nations is credited to cancer screening, management and treatment [2]. With the increased incidence of CRC, national colorectal cancer screening programmes were encouraged and initiated in a number of Asian countries to ensure early detection and treatment of CRC, with a view to lower the CRC mortality rates $[3,4]$. According to a retrospective study spanning from 2007 to 2017, the median survival period for colorectal cancer patients in Brunei Darussalam was 57.0 years [5].

Mutations in the RAS gene family can be found in in $20 \%$ to $25 \%$ of human cancers [6]; with a higher prevalence in colon, lung and pancreatic cancers [7]. Of the known mutations, $85 \%$ are associated with KRAS, whereas mutations in NRAS and HRAS make up of the remaining $12 \%$ and $3 \%$, respectively $[6,7]$. KRAS mutations account for approximately $40 \%$ of CRC cases, with approximately $80 \%$ of the mutations within codon 12 of the gene followed by mutations in codon $13(5 \%)$ [9-12]. The remaining mutations are found within codons 61, 117, 146 and 153 [13]. Most detected KRAS mutations are missense mutations. These single nucleotide mutations give rise to different amino acid substitutions that result in various downstream pathways of the Ras proteins [14]. The Ras mutations in codon 12 can give rise to either G12D, G12A, G12R, G12C, G12S, or G12V with the most common mutations being G12D and G12V. The most frequent mutation found in KRAS codon 13 results in G13D $[8,10]$. KRAS mutants G12D and G12V show different GTP hydrolysis rates, which can be translated to differential coupling with an activation of Ras effector [15]. For example, RasG12C or RasG12V activates the Ral signalling pathway and decreases growth factor dependent Akt activation, while KRAS G12D mutant activates the PI3K and MEK signalling pathways instead [14]. Therefore, different KRAS mutations are associated with distinctive clinical phenotypes, such as site of tumour location as well as site and rate of metastasis. Consequently, these mutants also confer varying sensitivity to chemotherapy and radiotherapy [14]. Currently, an inhibitor developed against KRAS G12C mutant is in clinical trial [16].

As Ras proteins are involved in the EGFR-RAS-RAF-MEK-ERK pathway, activating mutations around the nucleotide-binding pocket that locked Ras in active conformation result in constitutive signalling and therefore, proliferation of the cells [17]. Current evidence suggests RAS mutation status in metastatic CRC as both predictive and prognostic biomarker [10]. In addition, patients with metastatic colorectal cancer ( $\mathrm{mCRC}$ ) stage IV showed more aggressive tumour phenotype depending on the specific KRAS mutation present [18].

As K-ras is downstream of EGFR signalling pathway, mutant KRAS attenuates anti-EGFR therapies [19]. Thus, patients with mutant KRAS respond poorly to anti-EGFR monoclonal antibodies such as Cetuximab and Panitumumab $[20,21]$. In fact, Cetuximab or Panitumumab has very low response rate of $3 \%$ for mutated KRAS statuses [22], especially with mutations found within codons 12 and 13 [23]. The analysis of KRAS status is very important before the selection of targeted therapies as different therapies showed different response rates [24]. Testing for KRAS status is a prequisite to initiate anti EGFR based targeted treatment in metastatic CRC $[25,26]$. 
In this study, we aim to investigate the survival outcomes of mCRC patients in Brunei Darussalam with regards to the KRAS status of the patient, location of primary tumour and metastasis sites. We also attempt to correlate the various KRAS mutations to the patient survival outcomes in accordance to the patient's gender, age, site of primary tumour and metastatic location. These data may grant insights to the prognosis of patients and influence the treatment guidelines for CRC patients, especially for advanced $\mathrm{mCRC}$ patients treated in Brunei Darussalam.

\section{MATERIALS AND METHODS}

\section{Data collection}

This is a retrospective study to investigate the survival outcome of metastatic Colorectal cancer (mCRC) patients in Brunei Darussalam. Ethical approval for the study was obtained from PAPRSB Institute of Health Sciences Medical and Research Ethics Committee (Reference: UBD/HIS/B3/8 dated 19 April 2018). The study was conducted at The Brunei Cancer Centre (TBCC), Brunei Darussalam. Data of all mCRC patients diagnosed between 1 January 2013 and 31 December 2017 were collected and followed up until 30 April 2018. The data collected were age, gender, race, date of diagnosis, site of primary tumour, metastatic sites and the patients' tumour molecular analysis of KRAS mutation status (either KRAS mutated or KRAS wild-type). KRAS mutation status was based on quantitative PCR results testing for missense mutations on codon 12 and 13 of KRAS from CAP accredited diagnostic laboratory in National University Hospital of Singapore. The diagnostic date was the date of colonoscopy or sigmoidoscopy, or other diagnostic technique done. The metastatic sites were classified into either liver, lungs or others (inclusive of bone, brain, bladder and reproductive organs). Exclusion criteria were patients with known NRAS status, uncontactable patients and absence of metastasis. Known $N R A S$ status was excluded to obtain a non-biased population of KRAS. Uncontactable patients refer to patients that were not followed up by the end of the follow up period.

\section{Data analysis}

Overall survival (OS) refers to total duration in months between a patients' date of diagnosis to the end of the follow up period or date of termination (date of death). The status of the patients (whether the patient was alive or not at the time of study), gender, age, site of primary tumour, metastasis location, RAS status and mutated codon were documented. Primary tumours located in the ileocecal valve, cecum, ascending colon to the transverse colon was classified as the right sided colon tumour(RCC), while the primary tumours found within the splenic flexure, descending colon, sigmoid and rectum were classified as left sided colon tumours(LCC). All duration of date are recorded in months. To correlate the survival impact of the metastatic site, we have categorised the patients in accordance to the two most common metastatic organs, that is, the liver and the lungs. In addition, the number of metastatic sites were taken into account and therefore, the OS based on either single or multiple metastatic site was studied. Survival analysis of $\mathrm{mCRC}$ with mutated KRAS was compared with that of wild-type KRAS. A further inspection on the survival outcome of different KRAS mutations, such as G12D, G12S, G12V and G12C in codon 12 and G13D in codon 13 was done.

\section{Statistical analysis}

Chi-squared test was used to compare the survival outcomes of mCRC patients, and Mann-Whitney $U$ test was used to compare the median ages of both groups. Kaplan-Meier survival curves were drawn and logrank test was used to compare the survival outcome between two groups (namely between gender, age groups, location of primary tumour in the colon, and KRAS status). Statistical analysis was 
conducted using SPSS version 17.0 and $R$ (ver.3.6.0). A $p$-value of $<0.05$ is considered statistically significant.

\section{RESULTS}

\section{Overall survival (OS)}

During the study period, a total of 105 patients with stage IV CRC were treated in TBCC. These patients were initially diagnosed by either sigmoidoscopy/colonoscopic histopathologic biopsy. They were classified as stage IV patients due to presence of metastatic tumour(s). Out of the 105 cases, 29 were excluded from the study due to the following reasons: unknown KRAS status ( $\mathrm{n}=20$ ), known NRAS status ( $n=2)$, and inability to contact at the end of the follow-up period $(n=7)$. Hence, 76 metastatic CRC ( $m C R C$ ) patients were included in this study, and they were followed up for a total of 1951 personmonths. Their median age was 58 years (range $=20-79$ years). (Table 1 ). At the end of the study period, $55.3 \%(n=42)$ of the patients died (Table 1$)$. The ratio of male $m C R C(n=48 ; 63.2 \%)$ to female mCRC patients ( $n=28 ; 36.8 \%)$ was close to $2: 1$. At the end of the study period, only $21(61.8 \%)$ of the males mCRC patients and $13(38.2 \%)$ of the female mCRC patients survived. There was no significant difference between survival outcome and gender $(p=0.821)$ (Table 1). The median OS was 29 months (95\% Cl 23.7-34.3), with males and females having median survival of 27 months ( $95 \% \mathrm{Cl} 20.3-33.7$ ) and 29 months ( $95 \% \mathrm{Cl} 23.7-34.3)$, respectively. There was no significant difference $(p=0.764)$ in terms of median survival periods between the two genders (Figure 2 left panel, Table 2) and also no significant difference in terms of the median survival based on median age distribution of 58 years old (Figure 2 middle panel).

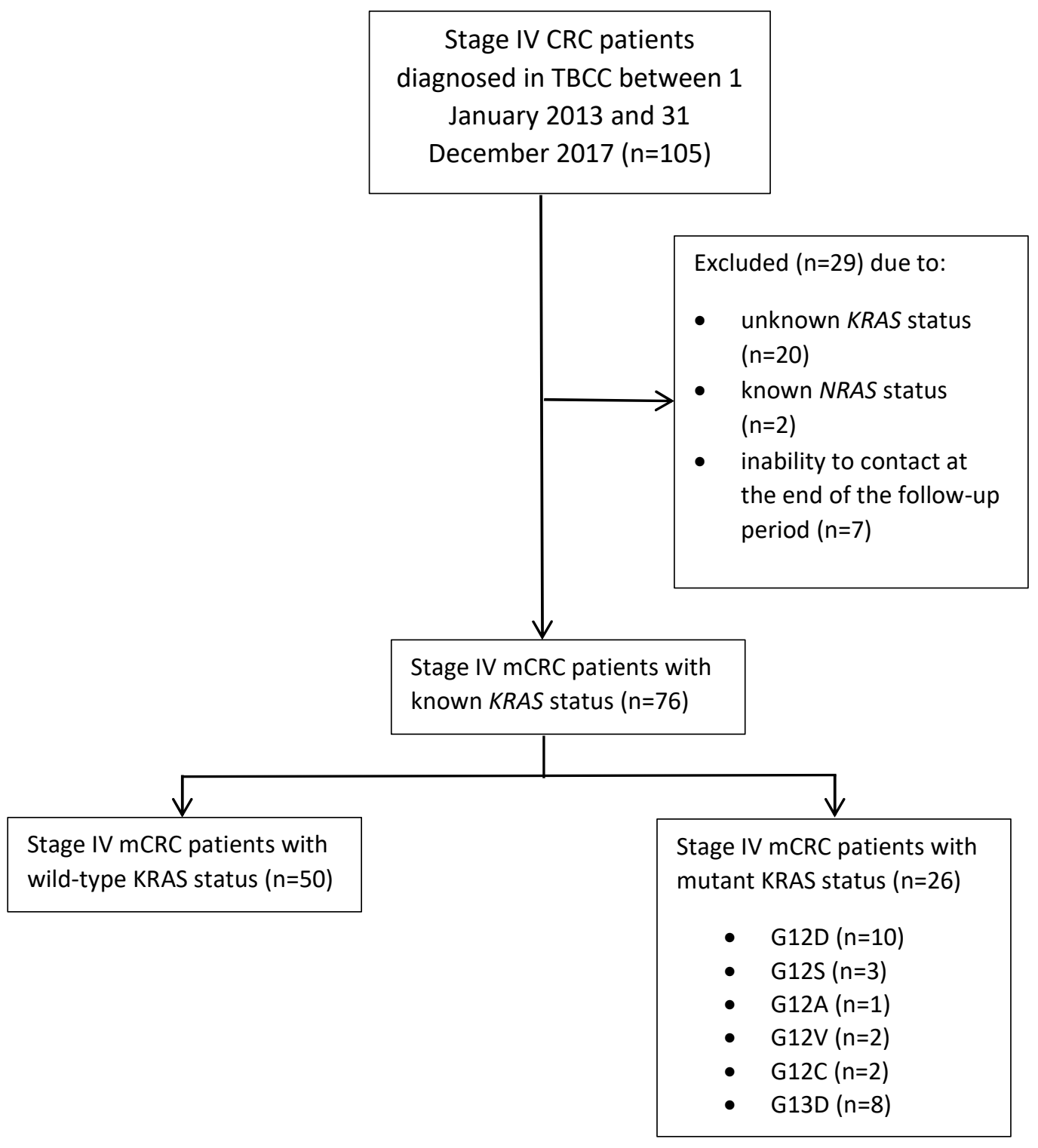


Table 1. Baseline characteristics of $m C R C$ patients $(N=76)$ and their survival outcomes

\begin{tabular}{|c|c|c|c|c|c|}
\hline \multicolumn{2}{|c|}{ Variables } & \multirow{2}{*}{$\begin{array}{c}\text { Total population } \\
\text { n (\%) }\end{array}$} & \multirow{2}{*}{$\begin{array}{c}\text { Dead }(n=42) \\
n(\%) \\
27(64.3)\end{array}$} & \multirow{2}{*}{$\begin{array}{c}\begin{array}{c}\text { Alive }(\mathbf{n}=34) \\
\text { n (\%) }\end{array} \\
21(61.8)\end{array}$} & \multirow{2}{*}{$\begin{array}{c}\text { p-value } \\
0.821\end{array}$} \\
\hline Gender & Male & & & & \\
\hline & Female & $28(36.8)$ & $15(35.7)$ & $13(38.2)$ & \\
\hline Age** & $\begin{array}{c}\text { Median in years } \\
(\mathrm{IQR})\end{array}$ & $58.0(16.0)$ & $58.0(13.0) 26$ to 79 & $56.0(22.0) 20$ to 78 & $0.507^{\#}$ \\
\hline \multirow[t]{2}{*}{ Location } & Right-sided & $14(18.4)$ & $6(14.3)$ & $8(23.5)$ & \multirow[t]{2}{*}{0.301} \\
\hline & Left-sided & $62(81.6)$ & $36(85.7)$ & $26(76.5)$ & \\
\hline \multirow[t]{2}{*}{ KRAS status } & Wild-type & $50(65.8)$ & $23(54.8)$ & $27(79.4)$ & \multirow[t]{2}{*}{0.024} \\
\hline & Mutated & $26(34.2)$ & $19(45.2)$ & $7(20.6)$ & \\
\hline \multirow[t]{3}{*}{ Site } & Colon & $19(25.0)$ & $8(19.0)$ & $11(32.4)$ & \multirow[t]{3}{*}{0.289} \\
\hline & Sigmoid colon & $36(47.4)$ & $23(54.8)$ & $13(38.2)$ & \\
\hline & Rectum & $21(27.6)$ & $11(26.2)$ & $10(29.4)$ & \\
\hline \multirow{2}{*}{$\begin{array}{c}\text { Number of } \\
\text { metastatic site(s) }\end{array}$} & Single & $23(30.3)$ & $7(16.7)$ & $16(47.1)$ & \multirow[t]{2}{*}{0.004} \\
\hline & Multiple & $53(69.7)$ & $35(83.3)$ & $18(52.9)$ & \\
\hline \multirow[t]{2}{*}{ Liver metastasis } & Yes & $60(78.9)$ & $32(76.2)$ & $28(82.4)$ & \multirow[t]{2}{*}{0.512} \\
\hline & No & $16(21.1)$ & $10(23.8)$ & $6(17.6)$ & \\
\hline \multirow[t]{2}{*}{ Lung Metastasis } & Yes & $42(55.3)$ & $29(69.0)$ & $13(38.2)$ & \multirow[t]{2}{*}{0.007} \\
\hline & No & $34(44.7)$ & $13(31.0)$ & $21(61.8)$ & \\
\hline \multirow[t]{2}{*}{ *Other metastasis } & Yes & $32(42.1)$ & $21(50.0)$ & $11(32.4)$ & \multirow[t]{2}{*}{0.121} \\
\hline & No & $44(57.9)$ & $21(50.0)$ & $23(67.6)$ & \\
\hline
\end{tabular}

Note: The whole numbers denote the data while the percentages are in parentheses. The p-values are derived using Pearson's Chi-Squared tests, apart from age of survival median. "The age of survival median is derived using Mann-Whitney $U$ test. * Other metastasis refers to any site other than liver and lung. Bold indicates significant values of $p<0.05$. 
Table 2. Baseline characteristics of $m C R C$ patients $(N=76)$ and the medians of their survival in months

\begin{tabular}{|c|c|c|c|c|}
\hline \multicolumn{2}{|c|}{ Variables } & $\begin{array}{c}\text { Total population } \\
\text { n (\%) }\end{array}$ & $\begin{array}{l}\text { Median survival in months } \\
\text { (95\% confidence interval) }\end{array}$ & P-value \\
\hline \multicolumn{2}{|c|}{ Overall } & $76(100)$ & $29(23.7-34.3)$ & - \\
\hline \multirow{2}{*}{ Gender } & Male & $48(63.2)$ & $27(20.3-33.7)$ & \multirow{2}{*}{0.764} \\
\hline & Female & $28(36.8)$ & $29(23.7-34.3)$ & \\
\hline \multirow{2}{*}{ Age } & $\leq 58$ & 41 (53.9) & $29(22.0-35.0)$ & \multirow{2}{*}{0.741} \\
\hline & $>58$ & $35(46.1)$ & $29(22.3-35.7)$ & \\
\hline \multirow{2}{*}{ location } & right-sided & $14(18.4)$ & - & \multirow{2}{*}{0.118} \\
\hline & Left-sided & $62(81.6)$ & $26(22.3-29.7)$ & \\
\hline \multirow{2}{*}{ KRAS status } & wild-type & $50(65.8)$ & $35(22.1-47.9)$ & \multirow{2}{*}{0.017} \\
\hline & mutated & $26(34.2)$ & $25(18.3-31.7)$ & \\
\hline \multirow{3}{*}{ Site } & Colon & $19(25.0)$ & - & \multirow{3}{*}{0.016} \\
\hline & Sigmoid colon & $36(47.4)$ & $25(20.8-29.2)$ & \\
\hline & Rectum & $21(27.6)$ & $34(28.4-39.6)$ & \\
\hline \multirow{2}{*}{$\begin{array}{c}\text { Number of } \\
\text { Metastatic site(s) }\end{array}$} & Single & $23(30.3)$ & - & \multirow{2}{*}{0.047} \\
\hline & multiple & $53(69.7)$ & $27(23.3-30.7)$ & \\
\hline \multirow{2}{*}{ Metastasis } & Liver & "60 (78.9) & $29(20.1-37.9)$ & $0.652^{*}$ \\
\hline & Lungs & ${ }^{\# 42(55.3)}$ & $25(22.3-27.7)$ & $0.011^{*}$ \\
\hline
\end{tabular}

The $p$-values are derived using logrank test, with $p$-values $<0.05$ being statistically significant. Bold indicates significant values of $p<0.05$. \#These cases could be overlapping for a patient with two or more metastatic sites. 

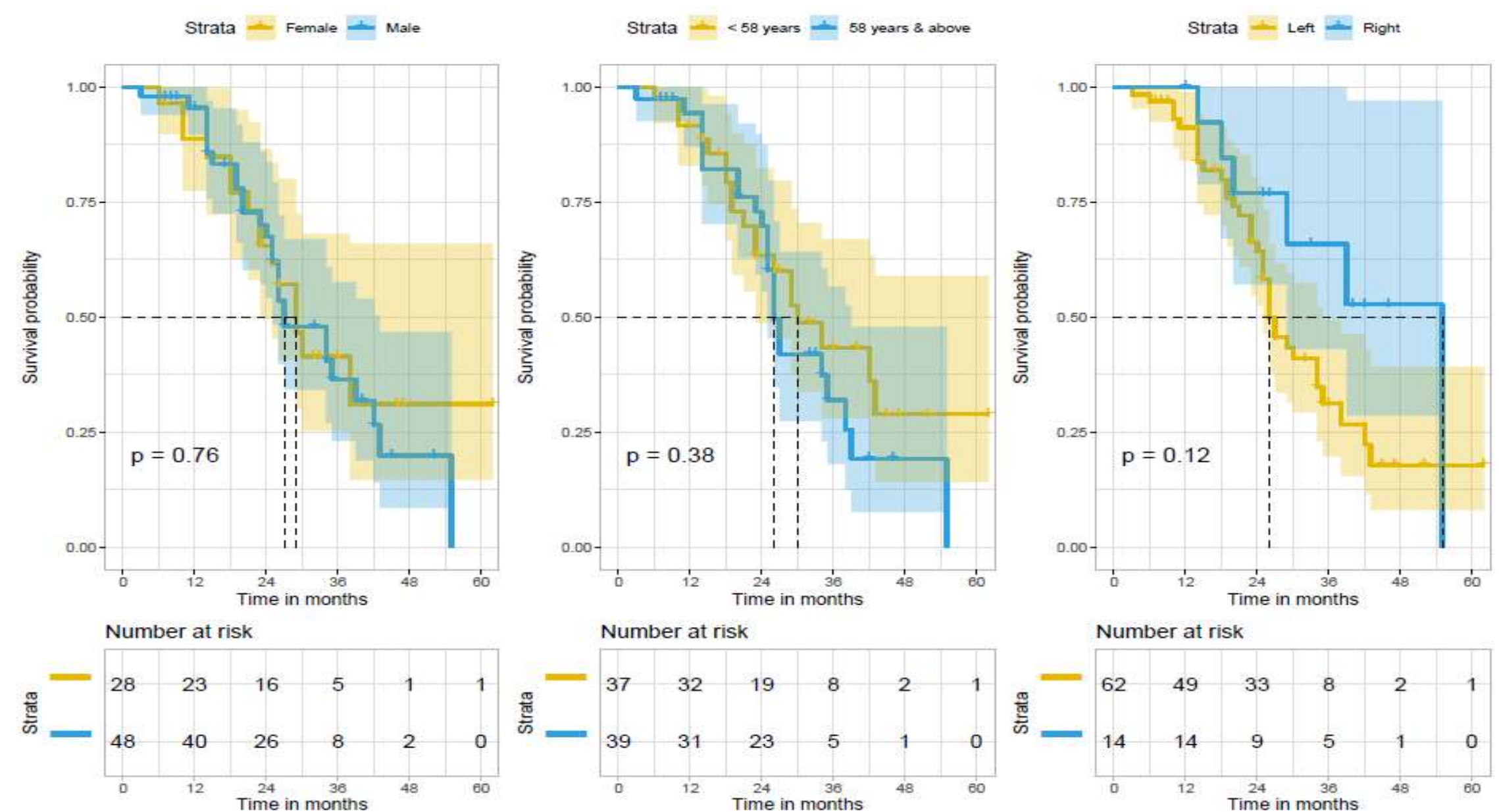

Figure 2. (Left) Survival outcomes of mCRC patients $(n=76)$ based on gender. P-value is derived from the log-rank test comparing the 2 Kaplan Meier curves for females (in yellow) and males (in blue). The shaded areas indicate the $95 \%$ confidence intervals for each group. (Middle) Survival outcomes of mCRC patients $(n=76)$ based on age distribution, with the median survival age of 58 years old as the cut-off point ( $<58$ years old in yellow; 58 years old and above in blue). (Right) Survival analysis of mCRC patients $(n=76)$ based on the site of primary tumour in the colon (Left colon in yellow; Right colon in blue). 
Table 3. Baseline characteristics of the mutant KRAS mCRC patients ( $\mathrm{N}=26)$

\begin{tabular}{|c|c|c|c|c|c|}
\hline \multicolumn{2}{|c|}{ Variable } & \multirow{3}{*}{$\begin{array}{c}\begin{array}{c}\text { Total population } \\
\text { N (\%) }\end{array} \\
15(57.7) \\
11(42.3)\end{array}$} & \multirow{2}{*}{$\begin{array}{c}\begin{array}{c}\text { Dead } \\
\mathrm{n}(\%)(\mathrm{n}=19)\end{array} \\
11(57.9) \\
\end{array}$} & \multirow{2}{*}{$\begin{array}{c}\begin{array}{c}\text { Alive } \\
\text { n (\%) (n=7) }\end{array} \\
4(57.1)\end{array}$} & \multirow{3}{*}{\begin{tabular}{|c|} 
p-value \\
0.973 \\
\end{tabular}} \\
\hline \multirow[t]{2}{*}{ Gender } & Male & & & & \\
\hline & Female & & $8(42.1)$ & $3(42.9)$ & \\
\hline Age & $\begin{array}{l}\text { Median in years (IQR, } \\
\text { min-max) }\end{array}$ & $60.0(12.0,39-78)$ & $58.0(10.0,39-73)$ & $67.0(9.0,52-78)$ & 0.035 \\
\hline \multirow[t]{2}{*}{ Location } & Right-sided & $7(26.9)$ & $3(15.8)$ & $4(57.1)$ & \multirow[t]{2}{*}{0.035} \\
\hline & Left-sided & $19(73.1)$ & $16(84.2)$ & $3(42.9)$ & \\
\hline \multirow{3}{*}{$\begin{array}{l}\text { Site of primary } \\
\text { tumour }\end{array}$} & Colon & $7(26.9)$ & $3(15.8)$ & $4(57.1)$ & \multirow[t]{3}{*}{0.080} \\
\hline & Sigmoid colon & $11(42.3)$ & $10(52.6)$ & $1(14.3)$ & \\
\hline & Rectum & $8(30.8)$ & $6(31.6)$ & $2(28.6)$ & \\
\hline \multirow{2}{*}{$\begin{array}{l}\text { Number of metastatic } \\
\text { site(s) }\end{array}$} & Single & $5(19.2)$ & $1(5.3)$ & $4(57.1)$ & \multirow[t]{2}{*}{0.003} \\
\hline & multiple & $21(80.8)$ & $18(94.7)$ & $3(42.9)$ & \\
\hline \multirow[t]{2}{*}{ Liver metastasis } & Yes & $20(76.9)$ & $13(68.4)$ & $7(100.0)$ & \multirow[t]{2}{*}{0.090} \\
\hline & No & $6(23.1)$ & $6(31.6)$ & $0(0.0)$ & \\
\hline \multirow[t]{2}{*}{ Lung Metastasis } & Yes & $18(69.2)$ & $15(78.9)$ & $3(42.9)$ & \multirow[t]{2}{*}{0.077} \\
\hline & No & $8(30.8)$ & $4(21.1)$ & $4(57.1)$ & \\
\hline \multirow[t]{2}{*}{ Other metastasis } & Yes & $1(3.8)$ & $1(5.3)$ & $0(0.0)$ & \multirow[t]{2}{*}{0.536} \\
\hline & No & $25(96.2)$ & $18(94.7)$ & $7(100.0)$ & \\
\hline \multirow[t]{2}{*}{ Codon 12} & Yes & $18(69.2)$ & $14(73.7)$ & $4(57.1)$ & \multirow[t]{2}{*}{0.418} \\
\hline & No & $8(30.8)$ & $5(26.3)$ & $3(42.9)$ & \\
\hline \multirow[t]{2}{*}{ Codon 13} & Yes & $8(30.8)$ & $5(26.3)$ & $3(42.9)$ & \multirow[t]{2}{*}{0.418} \\
\hline & No & $18(69.2)$ & $14(73.7)$ & $4(57.1)$ & \\
\hline
\end{tabular}

Note: The whole numbers denote the data while the percentages are in parentheses. The p-values are derived using Pearson's Chi-Squared tests, apart from age of survival median. "The age of survival median is derived using Mann-Whitney $\mathrm{U}$ test. ${ }^{*}$ Other metastasis refers to any site other than liver and lung. Bold indicates significant values of $p<0.05$. 


\section{Table 4. Baseline characteristics of mutant KRAS mCRC patients $(\mathrm{N}=26)$ and the medians of their survival in months}

\begin{tabular}{|c|c|c|c|c|}
\hline \multicolumn{2}{|c|}{ Variable } & Total population & Median ( $95 \%$ confidence interval) & P-value \\
\hline \multicolumn{2}{|c|}{ KRAS mutation } & 26 & $25(18.3-31.7)$ & 0.017 \\
\hline \multirow{2}{*}{ Gender } & Male & $15(57.7)$ & $29(17.0-33.0)$ & \multirow{2}{*}{0.585} \\
\hline & Female & $11(42.3)$ & $25(13.5-44.5)$ & \\
\hline \multirow{2}{*}{ Age } & Below 58 & $13(46)$ & $18(9.8-26.2)$ & \multirow{2}{*}{0.105} \\
\hline & 58 and above & $15(54)$ & $26(20.1-31.9)$ & \\
\hline \multirow{2}{*}{$\begin{array}{c}\text { Location of Tumour in } \\
\text { colon }\end{array}$} & Right-sided & $7(26.9)$ & $25(19.0-31.0)$ & \multirow{2}{*}{0.284} \\
\hline & Left-sided & $19(73.1)$ & - & \\
\hline \multirow{3}{*}{ Primary Tumour Site } & Colon & $7(26.9)$ & - & \multirow{3}{*}{0.348} \\
\hline & Sigmoid colon & $11(42.3)$ & $20(10.3-29.7)$ & \\
\hline & Rectum & $8(30.8)$ & $29(18.9-39.1)$ & \\
\hline \multirow{2}{*}{ Metastatic site } & Liver & $20(76.9)$ & $29(22.1-35.9)$ & 0.027 \\
\hline & Lungs & $18(69.2)$ & $25(18.4-31.6)$ & 0.108 \\
\hline \multirow{2}{*}{$\begin{array}{c}\text { Number of metastatic } \\
\text { site(s) }\end{array}$} & Single & $5(19.2)$ & - & \multirow{2}{*}{$0.043^{*}$} \\
\hline & Multiple & $21(80.8)$ & $25(18.0-32.0)$ & \\
\hline \multirow{5}{*}{ codon 12} & G12D & $10(38.5)$ & $23(15.4-34.6)$ & \multirow{6}{*}{$0.003^{\#}$} \\
\hline & G12S & $3(11.5)$ & $25(13.8-36.2)$ & \\
\hline & G12A & $1(3.8)$ & - & \\
\hline & G12V & $2(7.7)$ & - & \\
\hline & G12C & $2(7.7)$ & - & \\
\hline codon 13 & G13D & $8(30.8)$ & $29(24.4-33.6)$ & \\
\hline
\end{tabular}

Note: The $p$-values are derived using logrank test, with $p$-values $<0.05$ being statistically significant. Bold indicates significant values of $p<0.05 . *$ These $p$-values were derived based on comparison with total number of mutant KRAS mCRC patients $(n=26)$. "\#his $p$-value was obtained via logrank estimate between codon 12 and codon 13 dead and survivor numbers. 

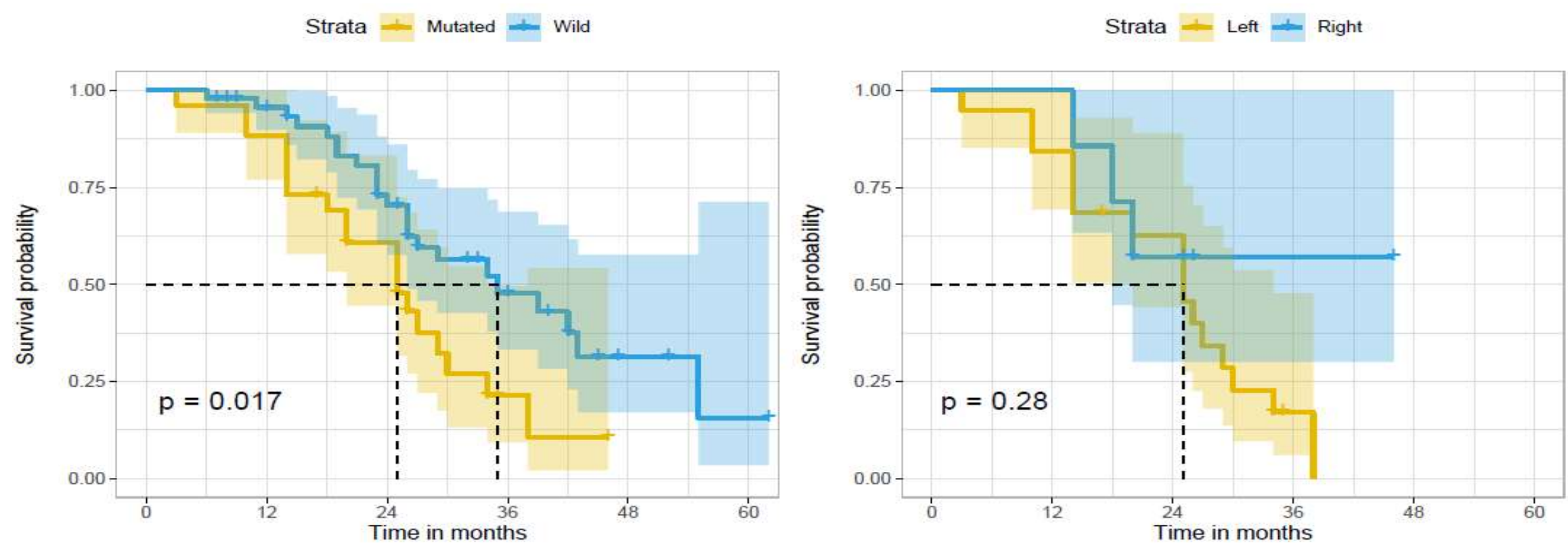

Number at risk

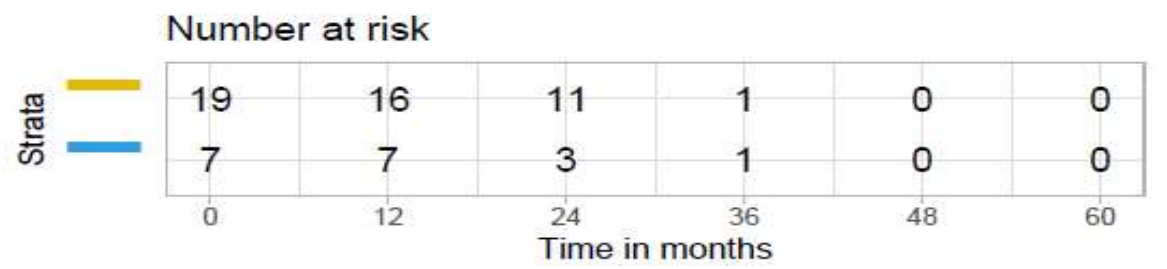

Figure 3. (Left) Survival outcomes of mCRC patients ( $n=76$ ) based on KRAS status (Mutated in yellow; Wild in blue). (Right) Survival outcomes of mCRC patients with KRAS mutation ( $n=26$ ), based on the site of primary tumour in the colon (Left colon in yellow; Right colon in blue). The shaded areas indicate the $95 \%$ confidence intervals for each group. Metastatic sites of $\mathrm{MCRC}$ patients and their effects on survival periods 


\section{Survival outcomes of mCRC patients based on gender, age of diagnosis, KRAS status and primary site of tumour}

81.6\% ( $n=62$ ) of mCRC patients were found to have the primary tumours on the left side of the colon. Among them, 36 died at the end of the study period, making up $85.7 \%$ of the death rates in this study (Table 1). Their median OS period was 26 months (95\% Cl $22.3-29.7$ ) (Table 2, Figure 2 right panel). Only $18.4 \%(n=14)$ mCRC cases with primary tumours found in the right side of the colon (abbreviated here as RCC for right-sided colorectal cancer) were recorded, out of which 6 died by the end of the study period, amounting to $14.3 \%$ of the deaths (Table 1 ). We were unable to calculate the median survival period for $\mathrm{mCRC}$ patients with RCC because more than $50 \%$ of the patients were alive at the end of the study period (Table 2). Intriguingly, 19 out of 26 (73.1\%) mutant KRAS mCRC patients were found to have primary tumours on the left-side of the colon (abbreviated here as LCC to refer to as left-sided colorectal cancer), while 7 out of $26(26.9 \%)$ had RCC (Table 3). There were significantly more deaths among those with LCC, when compared to RCC ( $p$-value $=0.035) .34 .2 \%(n=26)$ of the samples were mutant KRAS, generating a significant $p$-value of 0.024 .

19 of these 26 (73.1\%) mutant KRAS mCRC patients died, while 23 of 50 (46.0\%) wild-type KRAS mCRC patients died at the end of the study period, contributing to death rates of $45.2 \%$ and $54.8 \%$, correspondingly (Table 1). The median survival period of $\mathrm{MCRC}$ patients with mutant and wild-type KRAS was 25 months (95\% Cl: 18.3-31.7) and 35 months (95\% Cl: 22.1-47.9), individually (Table 2, Figure 3 left panel). Metastatic CRC patients with mutant KRAS were significantly more likely to have poorer median survival than $\mathrm{mCRC}$ patients with wild-type KRAS ( $p$-value $=0.017$, Table 2, Figure 3 left panel). Further analysis was conducted specifically on the $\mathrm{mCRC}$ patients with mutated KRAS status ( $n=26$, Tables 3 and 4). The median survival periods of male and female mutant KRAS mCRC patients were 29 months (95\% Cl: 17.0-33.0) and 25 months (95\% Cl: 13.5-44.5), accordingly (Table 4). Among the mutant KRAS mCRC patients, $73.1 \%(n=19)$ had LCC. Of these 19 patients, $84.2 \%(n=16)$ died at the end of the study period (Table 3 ). The median survival period of these 26 patients was 25 months (95\% Cl: 18.3-31.7) (Table 4, Figure 3 right panel).

The site of primary tumour was also classified either as in the colon, sigmoid colon or rectum. The primary tumours of most $\mathrm{mCRC}$ were found in the sigmoid colon (with $n=36$ ) constituting $47.4 \%$, followed by rectum ( $n=21,27.6 \%$ ) and colon ( $n=19,25.0 \%)$. There was no significant difference ( $p$ value $=0.289$ ) with regards to the survival outcomes and sites of primary tumours (Table 1$)$. The median survival period of $\mathrm{mCRC}$ patients with primary tumours found in the rectum (34 months [95\%Cl: 28.4-39.6]) was significantly longer ( $p$-value $=0.016$ ) than $\mathrm{mCRC}$ patients with primary tumours in the sigmoid colon ( 25 months [ $95 \% \mathrm{Cl}: 20.8$ - 29.2]). The median survival period of $\mathrm{mCRC}$ patients with primary tumours in the colon was non-calculable (Table 2), as more than half of the mCRC patients with tumours in colon were alive at the end of follow-up period. Correspondingly, for mutant KRAS mCRC patients, there was no significant difference between these patients with primary tumours located in either colon, sigmoid colon or rectum ( $p$-value $=0.080$, Table 3 ). No significant difference was found in the median survival periods between the mutant KRAS mCRC patients with primary tumours in the colon, sigmoid colon or rectum ( $p$-value $=0.348$ ) (Table 4$)$. 
We further investigated the number of metastatic sites detected in these mCRC patients. $30.3 \%$ ( $n=23)$ of the study population had a single metastatic site detected (either liver, or lung or any other organs), while $69.7 \%$ ( $n=53$ ) of the $76 \mathrm{mCRC}$ patients had two (double) or more metastatic sites (Table 1). mCRC patients with two or more metastatic sites were classified as multiple, regardless of the site of metastasis. There was a statistical significant difference between the number of metastatic sites and survival outcome ( $p$-value $=0.004$, Table 1 ). There was a statistically significance value of $p=0.047$ between the survival outcomes of $\mathrm{mCRC}$ patients with a single metastatic site and $\mathrm{mCRC}$ patients with multiple metastatic sites (Table 2). There was a significant difference between the numbers of metastatic sites and survival outcome ( $p$-value $=0.047$, Table 2 ). At the end of the study period, 7 of the 23 single metastatic site CRC patients died while 35 of the 53 multiple (two or more) metastatic sites CRC patients died, yielding deaths rates of $16.7 \%$ and $83.3 \%$, correspondingly ( $p$-value $=0.004$, Table 1).

In order to examine the survival outcomes of mutant KRAS $\mathrm{mCRC}$ patients $(\mathrm{n}=26)$ with varying number of metastatic sites, mutant KRAS mCRC patients were categorised in accordance to the number of metastatic sites. Out of the seven mutant KRAS mCRC patients who survived till the end of the study period, 4 (57.1\%) have one metastatic site while $3(42.9 \%)$ have two or more metastatic sites (Table 3). Mutant KRAS mCRC patients with multiple metastatic sites were significantly more likely to die by the end of the study period ( $p=0.003$, Table 3 ), as compared to mCRC patients with wild-type KRAS. The median survival period of mutant KRAS MCRC patients with one metastatic site was non-calculable, however, the median survival periods for mutant $\mathrm{mCRC}$ patients with two or more metastatic sites was 25 (95\% Cl: 18.0-32.0) (Table 4). Survival analysis revealed a significant difference between these two mutant KRAS patient groups ( $\mathrm{p}=0.043)$.

Two metastatic target organs (liver and lungs) were also examined. $78.9 \%(n=60)$ of the mCRC patients had liver metastasis, while $55.3 \%(n=42)$ had metastasis to the lungs. It should be noted that a mCRC patient may have metastasis to both the liver and the lungs. The survival rate of $\mathrm{mCRC}$ patients with liver metastasis was $46.7 \%$ ( $n=28)$, whilst the survival rate of $m C R C$ patients with lung metastasis was $30.9 \%(n=13)$. Chi-squared test showed no significant difference between the number of deaths and survival of $m C R C$ patients due to liver metastasis ( $p$-value of 0.512 ), but a significant difference with $p$-value of 0.007 was observed between the number of deaths and survival of $m C R C$ patients due to lung metastasis (Table 1). The median survival periods for $\mathrm{mCRC}$ patients with liver metastasis and lungs metastasis were at 29 months (95\% Cl: 20.1-37.9) and 25 (95\% Cl: 22.2-27.8), respectively. Survival analysis revealed a significant difference in the median survival times for $\mathrm{mCRC}$ patients with lung metastasis only ( $\mathrm{p}=0.011$, Table 2 ). Mutant KRAS mCRC patients were further analysed based on either liver or lung metastatic sites. Although majority of mutant KRAS mCRC patients with either metastatic site died, that is, 13 mutant KRAS mCRC patients with liver metastasis (68.4\%) and 15 mutant KRAS mCRC patients with lung metastasis $(78.9 \%)$ died at the end of the study period (Table 3).

\section{Clinical significance of the specific KRAS mutation}

The specific KRAS mutations detected in the mutant KRAS mCRC patients were studied. $69.2 \%(n=18)$ and $30.8 \%(n=8)$ of the mutant KRAS mCRC patients had mutations within codons 12 and 13, respectively (Tables 3 and 4). There was no significant difference between the survival outcomes of mutant KRAS patients with mutations in either codon 12 or 13 of the KRAS gene (Table 3). However, there is a significant difference in the median survival periods between the mutant KRAS mCRC patients with mutations in codon 12 and those with mutation in codon 13 of the KRAS gene ( $p$-value $=0.003$, Table 4). In our study population, the highest KRAS mutation was G12D ( $n=10)(38.5 \%)$, 
followed by G13D ( $n=8)(30.8 \%)$. There were $11.5 \%(n=3)$ of G12S, followed by $7.7 \%$ each of G12V and G12C with $3.8 \%$ of G12A. Median survival periods for mutant KRAS mCRC patients possessing G12A, G12V and G12C missense mutations were non-calculable. Mutant KRAS mCRC patients with G12D, G12S and G13D had median survival periods of 23 months $(95 \% \mathrm{Cl} 15.4-34.6), 25$ months $(95 \% \mathrm{Cl} 13.8-$ 36.2 ) and 29 months ( $95 \% \mathrm{Cl} 24.4-33.6)$ (Table 4), correspondingly.

\section{DISCUSSION}

To our knowledge, this is the first study in Brunei Darussalam to analyse both the survival outcomes of metastatic CRC patients and those of mutant KRAS mCRC patients. Although a recent paper published on the survival rates and associated factors of CRC patients in Brunei Darussalam [5], investigation on survival outcomes of mutant KRAS mCRC patients and exploration on the various KRAS mutations in these patients are still in its infancy in this country. The reported median survival period was 57.0 months for CRC [5], while for $\mathrm{mCRC}$ patients, we estimated that the median survival period was 29.0 months. Within Asia, India was found to have the lowest survival rate of $31.2 \%$ for CRC patients while China has the highest with survival rate of $77 \%[27,28]$. The survival rate of $\mathrm{mCRC}$ patients found within this study was $44.7 \%$ while the reported five year survival rate for CRC reported by Leong et al was $49.6 \%$ [5].There are more cases of male $\mathrm{mCRC}$ patients than female mCRC patients and a slightly shorter survival period of the male mCRC patients in our study (Table 1). Prior research has indicated that gender contributes to survival outcomes and females were deemed to have better OS [29], possibly due to the protective effects of female sex hormones against CRC [30,31].

Despite the small population of Brunei Darussalam, Chi-squared analysis showed a significant difference between the survival outcomes of wild-type KRAS and mutant KRAS mCRC patients ( $p$-value of 0.024 ). This is further corroborated by Kaplan-Meier survival analysis shown in Table 2, whereby there is a statistical significant difference $(p$-value $=0.017)$. The poorer survival outcome of mutant KRAS mCRC patients as compared to those of wild-type KRAS has been established [32], as KRAS has been identified as one of the six driver genes from the TCGA database that drives metastatic CRC [33]. Large cohort studies have consistently illustrated that mutant KRAS was associated with metastasis in CRC patients, including lymphatic and distant metastases [33]. Early mutation of KRAS in the adenoma to carcinoma progression confers tumour growth advantage, enabling enhanced growth of the tumour [34]. Also, as Ras is part of Ras-Raf-MEK-ERK signalling pathway, a vital pathway that controls survival and proliferation and is linked to PI3K and AKT pathway that mediates cell death [35,36], a constitutive active Ras drives carcinogenesis. Pioneering work on the immune suppressive role of mutant KRAS (KRASG12D) revealed that mutant KRAS suppressed interferon regulatory factor (IRF2) expression, leading to increased myeloid-derived suppressor cells and poor T cell infiltration $[37,38]$. All these point to the aggressiveness of mutant KRAS gene in carcinogenesis.

The primary tumour of CRC has been classified as either on the right side of the colon (ileocecal valve, cecum, ascending colon to the transverse colon) or the left side of the colon (the splenic flexure, descending colon, sigmoid and rectum). A further categorisation of the primary tumour location on the left side of the colon refers to the sigmoid colon and rectum. In agreement with Buchwald et al (2018), we found that mCRC patients with primary tumours found in the rectum had better OS than those with primary tumours within the colon (Table 2) [39]. A limitation of our study is the lack of further sorting of the primary tumour, especially for the right side of the colon. There is an unusual high number of left-sided primary tumours $(n=62)$ as compared to right-sided primary tumours $(n=14)$ in these mCRC patients. Although most reports stated that KRAS mutation is associated with rightsided colon primary tumours in CRC $[40,41]$, we found that most of the KRAS mutations in our study population are found within the left-sided colon primary tumours (data not shown). Nevertheless, 
Table 3 illustrated that there was a significant difference in the survival outcome between the mutant KRAS mCRC patients with RCC and mutant KRAS MCRC with LCC patients. The poor survival outcome of mutant KRAS left-sided tumour mCRC patients was congruent to the findings of Charlton et al (2017) and Xie et al (2019) [41, 42]. Xie et al (2019) concluded that although KRAS mutations were in high occurrence in RCC than LCC, there was an association of KRAS mutations and poor prognosis in LCC, which was absent in RCC [42].

Increasing number of metastatic sites correlates with poorer survival outcomes in this study (Tables 1, 2 and 3). In Stage IV M1b Non-Small Cell Lung cancer, the number of metastases but not the location has been found to have an impact on the survival outcomes of the patients [43]. On the contrary, the number of metastases has no significant effect on survival in prostate cancer patients [44]. There are currently a few studies debating whether the impact of survival is dependent on the site of metastasis or the number of metastasis [45]. However, the primary tumour site of cancer may affects the survival of patients [46]. In this study, as for median survival periods, $78.9 \%$ of $\mathrm{mCRC}$ patients were found to have metastasis to the liver, while $55.3 \%$ of $\mathrm{mCRC}$ patients were found to have metastasis to the lungs. A higher proportion of $\mathrm{mCRC}$ patients was found to have metastasis to the liver due to the colon's anatomical situation with regards to the portal circulation [47]. In addition, $81.6 \%$ of mCRC patients in this study were found to have LCC and LCC was associated with higher incidence of liver metastasis [48]. Table 2 demonstrated that $\mathrm{mCRC}$ patients with metastasis to the lungs had significantly poorer survival outcome compared to $\mathrm{MCRC}$ patients with metastasis to the liver. Survival analysis estimated that $\mathrm{mCRC}$ patients with liver metastasis had an average of four months more survival period (Table 2). Majority of the $m C R C$ patients with lungs metastasis $(n=42)$ had metastasis to the liver $(n=60)$ too. Therefore, the number of metastases most likely determines the survival outcome, with metastasis to the lungs being an indicator of worse OS. On the other hand, there were more cases of metastasis to the lungs in mutant KRAS mCRC patients (69.2\%), instead of $55.3 \%$ in the overall study population of mCRC patients. This is in agreement with the work of Ghidini et al (2016). Compared to wild-type KRAS $\mathrm{mCRC}$ patients, mutant KRAS $\mathrm{mCRC}$ patients were found to have higher incidence of lung and brain metastases [49]. Taken together, in this study population, the number of metastatic sites accompany worsened OS, with metastasis to the lungs being a predictor of poor OS. Mutation in KRAS gene further worsened the prognosis.

$85 \%$ of KRAS mutation occurs in codons 12 and 13 . Codons G12V and G12D are the most common mutated gene found in KRAS gene in codon 12 [50], accounting for $70 \%$ of all KRAS mutation [51]. Various studies have associated specific KRAS mutations with different likelihood of survival [49,51]. Bai et al (2017) determined that G12V and G12D have been associated with an increased risk of CRC associated death [50], while Jones et al (2017) established that G12C and G12V were predictors of worse OS [52]. Between G12D, G12S and G13D KRAS mutations, our study corroborates that mutant KRAS mCRC patients with G12D have the lowest survival median at 23 months (95\% $\mathrm{Cl}$ 15.4-34.6). There is a lack of data for the median survival periods of mutant KRAS mCRC patients with G12A, G12V and $\mathrm{G} 12 \mathrm{C}$ mutations due to the small population. In codon $13, \mathrm{G} 13 \mathrm{D}$ is the most common KRAS mutation $[15,50]$ and this was the second most common specific KRAS mutation after G12D in our study with a survival median period of 29 (95\% Cl:24.2-33.6) months (Table 4). Similar to most studies, we obtained that mutant KRAS mCRC patient mutation in codon 13 had a comparably better OS than those with mutation in codon $12[14,50,52]$.

In conclusion, we found that mutant KRAS MCRC patients had a significantly poorer OS, which was shown to be worse when the primary tumours were found at the left side of the colon. Mutant KRAS 
mCRC patients with mutations in codon 12 were found to have shorter survival median periods than those with mutations within codon 13 .

\section{Authors' Contributions}

R.P. conceived the work. D.D, R.P., T.P.U. and S.K.L acquired data. R.P D.D., L.C. and Y.C.L analysed the data. D.D. wrote the first draft of the manuscript. D.D., R.P., L.C, S.K.L, Z.H.L., K.K and Y.C.L contributed towards the discussion and revision of the manuscript. All authors read and agreed to the final version of the manuscript.

\section{Acknowledgment}

We would like to thank the nurses at The Brunei Cancer Centre, Pantai Jerudong Specialist Centre for their assistance in data collection.

\section{Funding}

This research was supported by Universiti Brunei Darussalam Competitive Research Grant UBD/OAVCRI/CRGWG(020)/180101 and UBD/RSCH/1.6/FICBF(B)/2019/005

\section{Conflicts of Interest}

The authors declare no conflict of interest.

\section{REFERENCES}

[1] Bray, F.; Ferlay, J.; Soerjomataram, I.; Siegel, R. L.; Torre, L. A.; Jemal, A. Global Cancer Statistics 2018: GLOBOCAN Estimates of Incidence and Mortality Worldwide for 36 Cancers in 185 Countries. CA. Cancer J. Clin., 2018, 68 (6), 394-424. https://doi.org/10.3322/caac.21492.

[2] Arnold, M.; Sierra, M. S.; Laversanne, M.; Soerjomataram, I.; Jemal, A.; Bray, F. Global Patterns and Trends in Colorectal Cancer Incidence and Mortality. Gut, 2017, 66 (4), 683-691. https://doi.org/10.1136/gutjnl-2015-310912.

[3] Lim, M. A.; Chong, V. H.; Ong, S. K. Y.; Lim, Y. C. Colorectal Cancer in Brunei Darussalam: An Overview and Rationale for National Screening Programme. Asian Pacific J. Cancer Prev., 2019, 20 (12), 3571-3580. https://doi.org/10.31557/APJCP.2019.20.12.3571.

[4] Sung, J. J. Y.; Lau, J. Y. W.; Goh, K. L.; Leung, W. K.; Chen, M. H.; Li, C. J.; Tandon, R.; Makharia, G.; Abdullah, M.; Fujita, R.; et al. Increasing Incidence of Colorectal Cancer in Asia: Implications for Screening. Lancet Oncol., 2005, 6 (11), 871-876. https://doi.org/10.1016/S1470-2045(05)70422-8.

[5] Leong, E.; Ong, S. K.; Madli, F.; Tan, A.; Lai, D.; Basir, N.; Ramlee, N.; Chong, V. H. Survival Rates and Associated Factors of Colorectal Cancer Patients in Brunei Darussalam. Asian Pac. J. Cancer Prev., 2020, 21 (1), 259-265. https://doi.org/10.31557/APJCP.2020.21.1.259.

[6] Schirripa, M.; Bergamo, F.; Cremolini, C.; Casagrande, M.; Lonardi, S.; Aprile, G.; Yang, D.; Marmorino, F.; Pasquini, G.; Sensi, E.; et al. BRAF and RAS Mutations as Prognostic Factors in Metastatic Colorectal Cancer Patients Undergoing Liver Resection. Br. J. Cancer, 2015, 112 (12), 1921-1928. https://doi.org/10.1038/bjc.2015.142.

[7] Cox, A. D.; Der, C. J. Ras History. Small GTPases, 2010, 1 (1), 2-27. https://doi.org/10.4161/sgtp.1.1.12178. 
[8] Tsuchida, N.; Murugan, A. K.; Grieco, M.; Tsuchida, N.; Kannan Murugan, A.; Grieco, M. Kirsten Ras* Oncogene: Significance of Its Discovery in Human Cancer Research. Oncotarget, 2016, 7 (29), 46717-46733. https://doi.org/10.18632/oncotarget.8773.

[9] Dinu, D.; Dobre, M.; Panaitescu, E.; Bîrlă, R.; losif, C.; Hoara, P.; Caragui, A.; Boeriu, M.; Constantinoiu, S.; Ardeleanu, C. Prognostic Significance of KRAS Gene Mutations in Colorectal Cancer--Preliminary Study. J. Med. Life, 2014, 7 (4), 581-587.

[10] Kondo, Y.; Hayashi, K.; Kawakami, K.; Miwa, Y.; Hayashi, H.; Yamamoto, M. KRAS Mutation Analysis of Single Circulating Tumor Cells from Patients with Metastatic Colorectal Cancer. BMC Cancer, 2017, 17 (1), 311. https://doi.org/10.1186/s12885-017-3305-6.

[11] Tan, C.; Du, X. KRAS Mutation Testing in Metastatic Colorectal Cancer. World Journal of Gastroenterology. 2012. https://doi.org/10.3748/wjg.v18.i37.5171.

[12] Schirripa, M.; Cremolini, C.; Loupakis, F.; Morvillo, M.; Bergamo, F.; Zoratto, F.; Salvatore, L.; Antoniotti, C.; Marmorino, F.; Sensi, E.; et al. Role of NRAS Mutations as Prognostic and Predictive Markers in Metastatic Colorectal Cancer. Int. J. Cancer, 2015, 136 (1), 83-90. https://doi.org/10.1002/ijc.28955.

[13] Haigis, K. M. KRAS Alleles: The Devil Is in the Detail. Trends in cancer, 2017, 3 (10), 686-697. https://doi.org/10.1016/j.trecan.2017.08.006.

[14] Renaud, S.; Guerrera, F.; Seitlinger, J.; Costardi, L.; Schaeffer, M.; Romain, B.; Mossetti, C.; Claire-Voegeli, A.; Filosso, P. L.; Legrain, M.; et al. KRAS Exon 2 Codon 13 Mutation Is Associated with a Better Prognosis than Codon 12 Mutation Following Lung Metastasectomy in Colorectal Cancer. Oncotarget, 2017, 8 (2), 2514-2524.

https://doi.org/10.18632/oncotarget.13697.

[15] Hammond, D. E.; Mageean, C. J.; Rusilowicz, E. V; Wickenden, J. A.; Clague, M. J.; Prior, I. A. Di Ff Erential Reprogramming of Isogenic Colorectal Cancer Cells by Distinct Activating KRAS Mutations. 2015. https://doi.org/10.1021/pr501191a.

[16] Canon, J.; Rex, K.; Saiki, A. Y.; Mohr, C.; Cooke, K.; Bagal, D.; Gaida, K.; Holt, T.; Knutson, C. G.; Koppada, N.; et al. The Clinical KRAS(G12C) Inhibitor AMG 510 Drives Anti-Tumour Immunity. Nature, 2019, 575 (7781), 217-223. https://doi.org/10.1038/s41586-019-1694-1.

[17] Serebriiskii, I. G.; Connelly, C.; Frampton, G.; Newberg, J.; Cooke, M.; Miller, V.; Ali, S.; Ross, J. S.; Handorf, E.; Arora, S.; et al. Comprehensive Characterization of RAS Mutations in Colon and Rectal Cancers in Old and Young Patients. Nat. Commun., 2019, 10 (1), 1-12. https://doi.org/10.1038/s41467-019-11530-0.

[18] Margonis, G. A.; Kim, Y.; Sasaki, K.; Samaha, M.; Amini, N.; Pawlik, T. M. Codon 13 KRAS Mutation Predicts Patterns of Recurrence in Patients Undergoing Hepatectomy for Colorectal Liver Metastases. Cancer, 2016, 122 (17), 2698-2707. https://doi.org/10.1002/cncr.30085.

[19] Palomba, G.; Cossu, A.; Paliogiannis, P.; Pazzola, A.; Baldino, G.; Scartozzi, M.; lonta, M. T.; Ortu, S.; Capelli, F.; Lanzillo, A.; et al. Prognostic Role of KRAS Mutations in Sardinian Patients with Colorectal Carcinoma. Oncol. Lett., 2016, 12 (2), 1415-1421. https://doi.org/10.3892/ol.2016.4798.

[20] Heinemann, J. C. V. E. V; Weikersthal, L. F. Von; Kaiser, U. V. Left - Sided Primary Tumors Are Associated with Favorable Prognosis in Patients with KRAS Codon 12 / 13 Wild - Type Metastatic Colorectal Cancer Treated with Cetuximab plus Chemotherapy : An Analysis of the AIO KRK - 0104 Trial. 2014, 1607-1614. https://doi.org/10.1007/s00432-014-1678-3.

[21] Knijn, N.; Mekenkamp, L. J. M.; Klomp, M.; Vink-Börger, M. E.; Tol, J.; Teerenstra, S.; Meijer, J. 
W. R.; Tebar, M.; Riemersma, S.; van Krieken, J. H. J. M.; et al. KRAS Mutation Analysis: A Comparison between Primary Tumours and Matched Liver Metastases in 305 Colorectal Cancer Patients. Br. J. Cancer, 2011, 104 (6), 1020-1026.

https://doi.org/10.1038/bjc.2011.26.

[22] Fernandez-Medarde, A.; Santos, E. Ras in Cancer and Developmental Diseases. Genes Cancer, 2011, 2 (3), 344-358. https://doi.org/10.1177/1947601911411084.

[23] Nakamura, M.; Aoyama, T.; Ishibashi, K.; Tsuji, A. Randomized Phase II Study of Cetuximab versus Irinotecan and Cetuximab in Patients with Chemo - Refractory KRAS Codon G13D Metastatic Colorectal Cancer ( G13D - Study ). Cancer Chemother. Pharmacol., 2017, 79 (1), 29-36. https://doi.org/10.1007/s00280-016-3203-7.

[24] Binefa, G.; Rodriguez-Moranta, F.; Teule, A.; Medina-Hayas, M. Colorectal Cancer: From Prevention to Personalized Medicine. World J. Gastroenterol., 2014, 20 (22), 6786-6808. https://doi.org/10.3748/wjg.v20.i22.6786.

[25] Linardou, H.; Dahabreh, I. J.; Kanaloupiti, D.; Siannis, F.; Bafaloukos, D.; Kosmidis, P.; Papadimitriou, C. A.; Murray, S. Assessment of Somatic K-RAS Mutations as a Mechanism Associated with Resistance to EGFR-Targeted Agents: A Systematic Review and Meta-Analysis of Studies in Advanced Non-Small-Cell Lung Cancer and Metastatic Colorectal Cancer. Lancet Oncol., 2008, 9 (10), 962-972.

[26] Deschoolmeester, V.; Baay, M.; Specenier, P.; Lardon, F.; Vermorken, J. B. A Review of the Most Promising Biomarkers in Colorectal Cancer: One Step Closer to Targeted Therapy. Oncologist, 2010, 15, 699-731. https://doi.org/10.1634/theoncologist.2010-0025.

[27] Yeole, B. B.; Sunny, L.; Swaminathan, R.; Sankaranarayanan, R.; Parkin, D. M. PopulationBased Survival from Colorectal Cancer in Mumbai, (Bombay) India. Eur. J. Cancer, 2001, 37 (11), 1402-1408. https://doi.org/10.1016/S0959-8049(01)00108-3.

[28] Fang, Y. J.; Wu, X. J.; Zhao, Q.; Li, L. R.; Lu, Z. H.; Ding, P. R.; Zhang, R. X.; Kong, L. H.; Wang, F. L.; Lin, J. Z.; et al. Hospital-Based Colorectal Cancer Survival Trend of Different Tumor Locations from 1960s to 2000s. PLoS One, 2013, 8 (9), 2-9. https://doi.org/10.1371/journal.pone.0073528.

[29] Yang, Y.; Wang, G.; He, J.; Ren, S.; Wu, F.; Zhang, J.; Wang, F. Gender Differences in Colorectal Cancer Survival: A Meta-Analysis. Int. J. Cancer, 2017, 141 (10), 1942-1949.

https://doi.org/10.1002/ijc.30827.

[30] Hendifar, A.; Yang, D.; Lenz, F.; Lurje, G.; Pohl, A.; Lenz, C.; Yan, N.; Wu, Z.; Lenz, H. J. Gender Disparities in Metastatic Colorectal Cancer Survival. Clin. Cancer Res., 2009, 15 (20), 63916397. https://doi.org/10.1158/1078-0432.CCR-09-0877.

[31] Majek, O.; Gondos, A.; Jansen, L.; Emrich, K.; Holleczek, B.; Katalinic, A.; Nennecke, A.; Eberle, A.; Brenner, H. Sex Differences in Colorectal Cancer Survival: Population-Based Analysis of 164,996 Colorectal Cancer Patients in Germany. PLoS One, 2013, 8 (7), 1-7. https://doi.org/10.1371/journal.pone.0068077.

[32] Phipps, A. I.; Buchanan, D. D.; Makar, K. W.; Win, A. K.; Baron, J. A.; Lindor, N. M.; Potter, J. D.; Newcomb, P. A. KRAS-Mutation Status in Relation to Colorectal Cancer Survival: The Joint Impact of Correlated Tumour Markers. Br. J. Cancer, 2013, 108 (8), 1757-1764. https://doi.org/10.1038/bjc.2013.118.

[33] Huang, D.; Sun, W.; Zhou, Y.; Li, P.; Chen, F.; Chen, H.; Xia, D.; Xu, E.; Lai, M.; Wu, Y.; et al. Mutations of Key Driver Genes in Colorectal Cancer Progression and Metastasis. Cancer 
Metastasis Rev., 2018, 37 (1), 173-187. https://doi.org/10.1007/s10555-017-9726-5.

[34] Palomba, G.; Colombino, M.; Contu, A.; Massidda, B.; Baldino, G.; Pazzola, A.; Ionta, M.; Capelli, F.; Trova, V.; Sedda, T.; et al. Prevalence of KRAS, BRAF, and PIK3CA Somatic Mutations in Patients with Colorectal Carcinoma May Vary in the Same Population: Clues from Sardinia. J. Transl. Med., 2012, 10, 178. https://doi.org/10.1186/1479-5876-10-178.

[35] Luo, H. R.; Hattori, H.; Hossain, M. A.; Hester, L.; Huang, Y.; Lee-Kwon, W.; Donowitz, M.; Nagata, E.; Snyder, S. H. Akt as a Mediator of Cell Death. Proc. Natl. Acad. Sci. U. S. A., 2003, 100 (20), 11712-11717. https://doi.org/10.1073/pnas.1634990100.

[36] Roberts, P. J.; Der, C. J. Targeting the Raf-MEK-ERK Mitogen-Activated Protein Kinase Cascade for the Treatment of Cancer. Oncogene, 2007, 26 (22), 3291-3310.

https://doi.org/10.1038/sj.onc.1210422.

[37] Hänggi, K.; Ruffell, B. Oncogenic KRAS Drives Immune Suppression in Colorectal Cancer. Cancer Cell, 2019, 35 (4), 535-537. https://doi.org/10.1016/j.ccell.2019.03.008.

[38] Liao, W.; Overman, M. J.; Boutin, A. T.; Shang, X.; Zhao, D.; Dey, P.; Li, J.; Wang, G.; Lan, Z.; Li, J.; et al. KRAS-IRF2 Axis Drives Immune Suppression and Immune Therapy Resistance in Colorectal Cancer. Cancer Cell, 2019, 35 (4), 559-572.e7. https://doi.org/10.1016/j.ccell.2019.02.008.

[39] Buchwald, P.; Hall, C.; Davidson, C.; Dixon, L.; Dobbs, B.; Robinson, B.; Frizelle, F. Improved Survival for Rectal Cancer Compared to Colon Cancer: The Four Cohort Study. ANZ J. Surg., 2018, 88 (3), E114-E117. https://doi.org/10.1111/ans.13730.

[40] Bylsma, L. C.; Gillezeau, C.; Garawin, T. A.; Kelsh, M. A.; Fryzek, J. P.; Sangaré, L.; Lowe, K. A. Prevalence of RAS and BRAF Mutations in Metastatic Colorectal Cancer Patients by Tumor Sidedness: A Systematic Review and Meta-Analysis. Cancer Med., 2019, No. July 2019, 10441057. https://doi.org/10.1002/cam4.2747.

[41] Charlton, M. E.; Kahl, A. R.; Greenbaum, A. A.; Karlitz, J. J.; Lin, C.; Lynch, C. F.; Chen, V. W. KRAS Testing, Tumor Location, and Survival in Patients With Stage IV Colorectal Cancer: SEER 2010-2013. J. Natl. Compr. Cancer Netw., 2017, 15 (12), 1484-1493. https://doi.org/10.6004/jnccn.2017.7011.

[42] Xie, M. Z.; Li, J. L.; Cai, Z. M.; Li, K. Z.; Hu, B. L. Impact of Primary Colorectal Cancer Location on the KRAS Status and Its Prognostic Value. BMC Gastroenterol., 2019, 19 (1), 1-9. https://doi.org/10.1186/s12876-019-0965-5.

[43] Gibson, A. J. W.; Li, H.; D'Silva, A.; Tudor, R. A.; Elegbede, A. A.; Otsuka, S. M.; Bebb, D. G.; Cheung, W. Y. Impact of Number versus Location of Metastases on Survival in Stage IV M1b Non-Small Cell Lung Cancer. Med. Oncol., 2018, 35 (9), 117. https://doi.org/10.1007/s12032018-1182-8.

[44] Guijarro, A.; Hernández, V.; de la Morena, J. M.; Jiménez-Valladolid, I.; Pérez-Fernández, E.; de la Peña, E.; Llorente, C. Influence of the Location and Number of Metastases in the Survival of Metastatic Prostatic Cancer Patients. Actas Urológicas Españolas, 2017, 41 (4), 226-233. https://doi.org/10.1016/j.acuro.2016.09.004.

[45] Yin, Z.; Tang, H.; Li, L.; Ni, J.; Yuan, S.; Lou, H.; Chen, M. Impact of Sites versus Number of Metastases on Survival of Patients with Organ Metastasis from Newly Diagnosed Cervical Cancer. Cancer Manag. Res., 2019, Volume 11, 7759-7766. https://doi.org/10.2147/CMAR.S203037.

[46] Riihimäki, M.; Thomsen, H.; Hemminki, A.; Sundquist, K.; Hemminki, K. Comparison of Survival 
of Patients with Metastases from Known versus Unknown Primaries: Survival in Metastatic Cancer. BMC Cancer, 2013, 13 (1), 36. https://doi.org/10.1186/1471-2407-13-36.

[47] Valderrama-Treviño, A. I.; Barrera-Mera, B.; Ceballos-Villalva, J. C.; Montalvo-Javé, E. E. Hepatic Metastasis from Colorectal Cancer. Euroasian J. Hepato-Gastroenterology, 2017, 7 (2), 166-175. https://doi.org/10.5005/jp-journals-10018-1241.

[48] Engstrand, J.; Nilsson, H.; Strömberg, C.; Jonas, E.; Freedman, J. Colorectal Cancer Liver Metastases - a Population-Based Study on Incidence, Management and Survival. BMC Cancer, 2018, 18 (1), 1-11. https://doi.org/10.1186/s12885-017-3925-x.

[49] Ghidini, M.; Petrelli, F.; Tomasello, G. Right Versus Left Colon Cancer: Resectable and Metastatic Disease. Curr. Treat. Options Oncol., 2018, 19 (6), 31. https://doi.org/10.1007/s11864-018-0544-y.

[50] Bai, B.; Shan, L.; Xie, B.; Huang, X.; Mao, W.; Wang, X.; Wang, D.; Zhu, H. Mutations in KRAS Codon 12 Predict Poor Survival in Chinese Patients with Metastatic Colorectal Cancer. Oncol. Lett., 2017, 3161-3166. https://doi.org/10.3892/ol.2017.7709.

[51] Sirisena, N. D.; Deen, K.; Eranda, D.; Mandawala, N.; Herath, P. The Pattern of KRAS Mutations in Metastatic Colorectal Cancer : A Retrospective Audit from Sri Lanka. BMC Res. Notes, 2017, 5-9. https://doi.org/10.1186/s13104-017-2731-5.

[52] Jones, R. P.; Sutton, P. A.; Evans, J. P.; Clifford, R.; McAvoy, A.; Lewis, J.; Rousseau, A.; Mountford, R.; McWhirter, D.; Malik, H. Z. Specific Mutations in KRAS Codon 12 Are Associated with Worse Overall Survival in Patients with Advanced and Recurrent Colorectal Cancer. Br. J. Cancer, 2017, 116 (7), 923-929. https://doi.org/10.1038/bjc.2017.37. 